\title{
AOR
}

Selected Papers of \#AolR2021:

The 22nd Annual Conference of the

Association of Internet Researchers

Virtual Event / 13-16 Oct 2021

\section{STRIVERS, MAINTAINERS, ACHIEVERS: NETWORKED TRAJECTORIES OF OLDER ADULTS LEARNING TO USE TECHNOLOGY DURING A PANDEMIC}

Will Marler

University of Zurich

\section{Introduction}

"Aging in place" in one's home is valued for enabling older adults to maintain "independence, autonomy, and connection to social support, including friends and family" (Wiles et al., 2012). Digital technology is designed as an ally for older adults to remain living in their homes and communities though older adults' have varying experiences and attitudes towards technology's role (Peek et al., 2016). During the COVID-19 pandemic, older adults were under the burden of "sheltering in place," remaining at home and out of physical contact with their social networks. Research has explored digital divides in older adults' technology skills and uses (Hunsaker \& Hargittai, 2018) and in their communication uptake during the pandemic (Nguyen et al., 2021). We lack an understanding of the on-the-ground experiences and trajectories of older adults seeking to adopt digital technologies to maintains social connection during the COVID-19 pandemic. What balance of independence and interdependence do older adults experience as they attempt to take up new devices and applications, such as tablets and video chat, during a period of physical distancing?

\section{Methods}

I conducted in-depth, remote interviews and participants observation with 12 older adults - nine women and three men who were white and Black in race - participating in a technology training program provided by a nonprofit organization in a midwestern U.S. city between December 2020 and July 2021. I logged 90 hours on Zoom and the phone in the remote fieldwork over this period, including classroom observation, interviews, "hanging out" with participants, checking in with staff and other community organizations, and volunteering. The training program provided lower-income older adults with a tablet, home Internet service, and a 10-week digital skills course held over Zoom. I interviewed eight of the participants longitudinally after they completed the program. These include six women and two men ranging from 60 to 90 years of age, 
including three Black participants. I conducted 42 hour-long Zoom or phone interviews with the eight longitudinal participants. I gained insights on the broader context of everyday life over Zoom interviews through "home tours" given by participants and hanging out and speaking about a variety of topics outside of interview questions. I attended eight tablet training classes, spoke as the graduation speaker for four cohorts, and conducted four volunteer sessions as a digital tutor. With the permission of five participants, I also began to observe their social media activity on Facebook, weaving these observations into interviews. I recruited participants and collected data through an ongoing process of informed consent and analyzed my data through grounded theory, allowing concepts to arise and testing them against future responses and observations.

\section{Findings}

I introduce "strivers," "achievers," and "maintainers" to describe different experiences of in(ter)dependence that emerged at the intersection of technology use and physical distancing for 12 participants during and after the technology training program. There are the oldest participants, who had the least digital skills and experience, aged 86 and 90, whom I call "strivers." A 10-week remote training course, a free tablet, and home Internet service was not enough for these strivers to develop an independent capacity to use Zoom and other features of their tablets as a means of social connection. The technology training program was itself the primary social outlet of these strivers during the period of fieldwork, aside from occasional family visits and phone calls from friends.

Different expressions of social needs shaped life satisfaction across strivers in the context of a failure to develop technological independence. Phone calls and occasional visits provided sufficient relief for Sarah, aged 86 , divorced, and living without any of her family in the city, who "never feels lonely, even when [she is] alone," and finds entertainment in reading and television. By contrast, Wilma, aged 90 , who lives alone and whose children occasionally visit from other cities, described herself as depressed before and after graduating from the program. Trouble with dexterity and memory prevented Wilma from gaining proficiency in Zoom, despite ongoing remote tutoring sessions. Zoom continued to represent "the outside world" of social possibility. In contrast, the satisfaction she gained from phone conversations with friends dwindled over the months with the imposed monotony of the pandemic: "No activities, no trips around town. We don't have anything to talk about!" Wilma acknowledged her social dependence and experienced greater discontent for having experienced though not realized the potential of Zoom to bring her into community contact once the program had ended.

While strivers sought but could not develop new digital capacities through a nonprofit program, the "achievers" were younger, in their early or mid-60s, and had used smartphones and social media for several years. Achievers used a level of existing digital skill to seize on a new provision of devices, services, and instruction and they solidified and developed existing social involvements, in degrees that varied based on pre-existing social networks. For example, Toni, 67 and never married, took on a greater role in her church as gatherings went virtual. Toni become involved in Zoom calls with a national group of women church leaders who had previously met in person elsewhere in the country where Toni was not inclined to travel. Finally, "maintainers" 
also had a level of digital proficiency entering the program and expanded their digital repertoires through skills gained in the program, though largely saw no shift in their social involvements. For example, Mandy, 60 and divorced, continued to maintain her social connections over her smartphone, where she was already familiar with her apps, while turning the tablet into a means of greater financial independence, downloading "couponing" apps and participating in paid studies with the use of a larger screen and faster processor.

\section{Conclusion}

The study proposes a typology for digital trajectories later in life. Independence is reflected among those who were able to translate provided technology resources into an expanded social presence during the pandemic, like Toni. Interdependence describes those whose need for others grew with the addition of needed technology support. A glimpse at digital possibilities and the lack of sufficient support to seize them led to a larger sense of alienation for those like Wilma. However, by declaring oneself "not lonely despite being alone," strivers like Sarah could declare independence despite failing to realize the promise of digital technology as a stand-in for in-person connection. Research on older adults and digital technology can benefit from examining not only the possession of digital skills and technology support, but also the meanings that older adults bring to their experiences of inclusion and exclusion as they adapt to digital technologies while aging - and sheltering - in place.

\section{References}

Hunsaker, A., \& Hargittai, E. (2018). A review of Internet use among older adults: New Media \& Society, 20(10), 3937-3954.

Nguyen, M. H., Hargittai, E., \& Marler, W. (2021). Digital Inequality in Communication During A Time of Physical Distancing: The Case of Covid-19. Computers in Human Behavior.

Peek, S. T. M., Luijkx, K. G., Rijnaard, M. D., Nieboer, M. E., Voort, C. S. van der, Aarts, S., Hoof, J. van, Vrijhoef, H. J. M., \& Wouters, E. J. M. (2016). Older Adults' Reasons for Using Technology while Aging in Place. Gerontology, 62(2), 226-237.

Quan-Haase, A., Williams, C., Kicevski, M., Elueze, I., \& Wellman, B. (2018). Dividing the Grey Divide. American Behavioral Scientist, 62(9), 1207-1228.

Wiles, J. L., Leibing, A., Guberman, N., Reeve, J., \& Allen, R. E. (2012). The meaning of "aging in place" to older people. The Gerontologist, 52(3), 357-366. 